\title{
Diagnostic Applications of the Platinum Electrode Catheter
}

\author{
C. E. ROTEM* AND H. MILLER
}

From the Cardiac Catheterization Laboratory, Stanford Medical Center, Palo Alto, California, U.S.A.

The purpose of the present report is to summarize the investigations carried out in this laboratory with an intracardiac platinum electrode catheter, and to recommend its wider use. It was used for recording intracavitary electrocardiographic tracings, for detecting left-to-right shunts during right heart catheterization, for detecting valvular insufficiency, and for short-term frequency stabilization (pace-making).

Intracardiac electrocardiography was apparently first carried out by Lenègre and Maurice (1945a, b). A No. 13 ureteric catheter carrying a gold electrode was used, and initially only right heart tracings were obtained. Hecht (1946) and Sodi-Pallares, Thomsen, and Soberón (1948) were probably the first to supply detailed descriptions of the morphology of intracavitary complexes, including the left heart chambers. Initially the left heart complexes were obtained by passing the catheter through existing septal defects or patent foramina ovalæ. However, Sodi-Pallares et al. (1950), Zimmerman and Hellerstein (1951), and many others have now studied these complexes by retrograde left ventricular catheterization. Localization of the aortic valve for precise coronary and aortic angiography is facilitated by observing the intracardiac electrocardiogram (Underhill et al., 1964). Composite catheters incorporating a platinum electrode in a standard Cournand Catheter (made by the U.S. Catheter and Instrument Corporation) became generally available about 1959 . With these, intracardiac electrocardiographic tracings could be recorded during routine heart catheterizations. The great utility and significance of the results obtained have been summarized by Watson (1964). As the catheter is introduced into the right atrium, entry into the coronary sinus, a defect, or a pulmonary

Received April 28, 1966.

* Present address: Shaughnessy Hospital, Vancouver 9, B.C., Canada. vein gives characteristic changes of the baseline. Contact between the tip of the catheter and the endocardium gives rise to an immediate elevation of the S-T segment in a typical "current of injury" pattern. The procedure enables the accurate location of the tip of the catheter through the observation of the amplified electrocardiograph signal on a cathode ray oscilloscope screen or on an oscillographic tracing, and thus precise blood sampling in both adults and children presents no problems. Further, changes in the shape of the tracing enable direct and definite diagnoses of such anomalies as Ebstein's malformation of the tricuspid valve, infundibular pulmonary stenosis, and others.

It is, however, possible to use the catheter described above for a much wider purpose than the recording of the intracardiac electrocardiogram. In particular, use has been made of the fact that some redox reactions occurring at the surface of a platinum electrode immersed in an electrolytic fluid such as blood, may, under certain conditions, proceed at a rate which is controlled by the local concentration of the electrolyte (and, to some extent, by the local flow velocity). This fact is, of course, widely used in applied electrochemistry (Glasstone, 1942). Misrahy and Clark (1956) first used the technique to measure blood flow velocities. It has been successfully applied to the detection of left-to-right intracardiac shunts, using an easily detectable and innocuous ion (such as hydrogen ${ }^{+}$or ascorbate), with any of the commonly used recorders (Clark and Bargeron, 1959a, b; Vogel, Grover, and Blount, 1962, 1963; Frommer, Pfaff, and Braunwald, 1961; Hugenholtz et al., 1963). Hydrogen has to be administered by inhalation, and this method will therefore be suitable only for the detection of leftto-right shunts.

As any septal defect of significant size is being closed by operation, it would be of great value to be able to use this method in order to estimate the size 
of a shunt. This would obviate the need to analyse numerous blood samples.

\section{METHOD OF INVESTIGATION}

Hydrogen is introduced into the blood-stream by the administration of a single breath of hydrogen gas to the patient. Part of the hydrogen crosses rapidly through the alveolar capillary membrane, and even through the walls of larger vessels (Sobol et al., 1963). These walls are more permeable to hydrogen than to atmospheric gases. It dissolves in the blood and, in patients with a normal capillary bed, appears in the left heart chambers within a few seconds. In the presence of a left-to-right shunt, some of the blood containing hydrogen will flow through the defect to the right side where its presence will be detected by the platinum electrode. The baseline of the intracardiac electrocardiogram will thereupon show a marked shift (up to $300 \mathrm{mV}$ ) with respect to a reference electrode outside the heart. For a purely qualitative indication of the presence of hydrogen (detection of a shunt) an ordinary electrocardiographic amplifier may be used to record the shift of the baseline.

Instead of hydrogen, ascorbate can be used as an indicator: this is injected into the left ventricle or atrium through the same catheter used for pressure determination, while a platinum electrode or probe will detect its arrival in the right ventricle or atrium. A typical curve is obtained as with hydrogen.

The input impedance of the instrument is such that mainly hydrogen ion concentration in the blood-stream passing the electrode is monitored. Commercially one could therefore calibrate the apparatus to read the concentration directly. However, in the absence of accurate knowledge of the local flow rate, no quantitative estimate of the amount of hydrogen passing the location of the electrode can be made.

The Catheters. (A) Platinum electrode cardiac catheters. These have a single lumen and a platinum electrode ring a few millimetres from the tip, flush with the catheter surface. The other end of the catheter carries a terminal for connexion to a recorder. This consists of a metal band to accommodate alligator clamps located near the Luer-Lok fitting. The catheter lumen is one size smaller than the comparable non-electrode type. It is available in sizes $5 \mathrm{~F}-9 \mathrm{~F}$ in lengths of 50 , 100 , and $125 \mathrm{~cm}$.

(B) Platinum probe. This is a multistrand stainless steel wire insulated with teflon (PTFE) size 0,60 in. $\left(152 \mathrm{~cm}\right.$.) long and with a $\frac{1}{8}$ in. $(3 \mathrm{~mm}$.) platinum tip*. It can be introduced through a $17 \mathrm{~T}$ hypodermic needle, a $6 \mathrm{~F}$ cardiac catheter, Stille needles, and some $18 \mathrm{~T}$ Cournand needles. The wire is radio-opaque and quite flexible. It is easily introduced percutaneously, which is a great advantage, and its progress can be monitored on the electrocardiographic recorder without fluoroscopic control.

(C) Bi-polar platinum electrode catheter. With this catheter two separate circuits, one from each electrode,

* This probe is commercially available from Davis Geck, Division of American Cyanamid Co.

$\mathbf{R}$ are used for simultaneous recording. Each of the electrodes has a separate outlet and a separate reference electrode. Any distance between the two electrodes may be ordered, but $10 \mathrm{~cm}$. is usually recommended. The double platinum electrode is available in sizes $6 \mathrm{~F}-$ $7 \mathrm{~F}$ and in lengths of 100 and $125 \mathrm{~cm} . \dagger$

Electrical Circuitry. The electrical connexion and recording circuitry of the single electrode are simple. One wire is connected via an alligator clamp to the proximal electrode terminal, and a second wire is connected to a German silver reference electrode on the patient's arm or leg. A third wire is connected to the patient's leg as a ground. The wires are connected to the D.C. input of an electrocardiographic recorder.

Possible electric shock hazards to the patient (Weinberg et al., 1962) should be considered and appropriate precautions taken. It is absolutely necessary that the recorder be properly grounded. If the patient is grounded and the recorder is not, then there could be a possibility of current flowing from the recorder through the patient. Attention has to be paid to keep all connexions dry. As a precaution, all other electrical equipment should be disconnected from the patient. In addition, keeping other electrical instruments at some distance will reduce interference and recorder background noise.

Some of the minor disadvantages of platinum electrode catheters as compared with other techniques are as follows.

(1) Slightly diminished flexibility compared to ordinary catheters of the same size.

(2) Because of the relatively smaller lumen, sampling through the electrode catheter is a little slower.

(3) There appears to be a somewhat increased tendency to develop arrhythmia when the catheter is passed through the tricuspid valve and through the right ventricular outflow tract.

The accepted method for the detection of left-to-right shunts in congenital heart disease has been based on the detection of a "step-up" in oxygen saturation between the venæ cavæ and pulmonary artery. Localization of the defect, when the catheter could not be passed through it, depends on the determination of the site of sudden increase in oxygen saturation. This requires the analysis of numerous blood samples, a long (and costly) procedure. The results are obtainable only a considerable time after the end of catheterization, except when direct reading oximeters are available. Finally, when the shunt is very small, blood oxygen analysis might be too insensitive and unreliable. In comparison, the use of the platinum electrode has made the diagnosis, and a fairly precise localization of the defect, easy, rapid, and cheap.

\section{TECHNIQUE}

The platinum electrode is placed in the pulmonary artery wedge position and connected by a shielded wire, as described above, to an electrocardiographic recorder. Since a positive hydrogen

† From United States Catheter \& Instrument Corporation. 
curve is usually obtainable in the wedge position in normal subjects, this first curve may serve as a control for the response of the electrode and system, though this is not essential. The tip of the catheter is then pulled back until it rests in the main pulmonary artery. Once a steady, interference-free intracavitary electrocardiogram is recorded, the instrument is dampened to $1 / 5 \mathrm{~cm}$. per $\mathrm{mV}$. Hydrogen gas is transferred to a one-litre rebreathing bag, having a mouthpiece, a two-way valve, and as little "dead" space as possible. The mouthpiece is put in the patient's mouth, his nose is clamped, and he is instructed to breathe room air normally. A thick needle is inserted into the neck of the rubber mouthpiece and connected to a pressure transducer. A strain-gauge amplifier then monitors the patient's respiratory curve. When a normal respiratory pattern is established and no interference is present on the tracing, the valve is turned and the patient takes one breath of hydrogen, exhaling it again into the bag. The deep breath of hydrogen is discernible on the respiratory curve tracing. Alternatively, a pneumograph may be used, or a platinum-tipped nasal probe. If no respiratory curve is being taken, a manual mark may be inserted on the electrocardiogram at the moment at which the two-way cock is turned. We have found that all methods work about equally well. A sudden deflection of the intracardiac cardiogram baseline will start at one to four seconds after the inhalation of hydrogen; if the catheter tip is in the right chambers this will signal the presence of a left-to-right shunt proximal to the probe. The time delay is termed "appearance" or "arrival time" (Fig. 1). Since the blood in the pulmonary artery presents a mixed venous sample, any left-to-right shunt should be detected there. If no shunt is present a "recirculation curve" will be obtained; this is a shallow slow drift rather than sharp deflection of the baseline appearing five to nine seconds after the inhalation (Fig. 2). This will occur in the pulmonary artery when there is no shunt or in any other chamber upstream of the shunt. Each curve should always be taken at least twice and should be reproducible. The inhalation can be repeated at $1 \frac{1}{2}$ to 2 -minute intervals. If the hydrogen curve suggests the presence of a shunt, the catheter is then pulled back into the right ventricular outflow tract, and the test is repeated. The catheter is slowly pulled back through the right ventricle and right atrium and the procedure is repeated until a "recirculation" curve is obtained. The defect has then been located at the level of the catheter tip for the previous test.

In our series, all patients had first undergone routine right heart catheterization with analysis of numerous samples of blood to detect any oxygen "step-up". The patients thus served as their own "controls" and the great majority have since undergone surgery. In this series there have been no "false positive" or "false negative" results when the tests were repeated with the hydrogen electrode.

As a further precaution in order to avoid all possible sources of false positive results, it is advisable to record simultaneously the arrival time in an artery. This would signal the rapid circulation time which may occur in "high output" states, where the upper limit of four seconds for the "appearance time" is obviously not applicable.

The detection of left-to-right shunts can be performed easily, rapidly, and with great accuracy as an out-patient procedure, using a platinum probe (Vogel et al., 1964). The procedure is technically easy, requires no fluoroscopic control, and no special preparation or sedation of the patient. Technical help is confined to handling the hydrogen and recorder. The cost of the test is very low and the information obtained reliable and immediate. The platinum probe described above is introduced percutaneously into an antecubital vein through a Cournand needle. The intracardiac cardiogram is monitored on the oscillographic screen and arrival of the platinum tip in the right atrium is signalled by the appearance of large $P$ waves, followed by small QRS complexes. The wire is then slowly advanced for another 2 to $5 \mathrm{~cm}$., whereupon the tip is usually carried by the blood-stream into the right ventricle. Arrival of the tip inside the ventricle is recognized by the appearance of small $P$ waves and very large QRS complexes. The wire is again advanced by about $2 \mathrm{~cm}$. and then drifts into the pulmonary artery where the QRS amplitude is smaller and the contour similar to that of an external electrocardiogram. Now a single breath of hydrogen is administered, as previously described, and the curve is observed. A sharp deep deflection within four seconds of the inhalation signifies the presence of a shunt. The test is repeated twice. As with the platinum electrode catheter, localization of the defect can be made fairly accurately by repeating the hydrogen inhalations when the electrode is at various levels inside the ventricle and the atrium, until the first recirculation curve is obtained.

The probe will occasionally curl up in the right atrium or descend into the inferior vena cava. This can be recognized when a greater than usual length of wire has been advanced without the typical ventricular complexes appearing. If this happens, the probe is gently pulled out to the point where the typical atrial complexes first reappear; it is then slowly advanced again for about $2 \mathrm{~cm}$. and allowed to drift into the right ventricle.

A most useful application of the platinum probe 


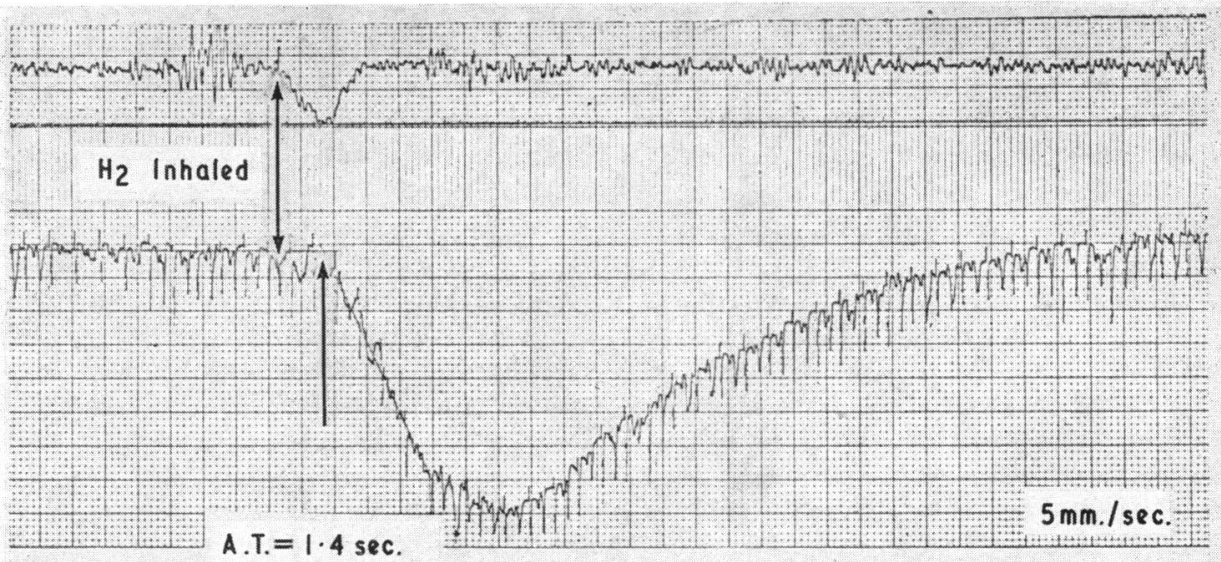

FIG. 1.-Positive response to hydrogen using a platinum electrode catheter, and recorded in the right venticle. Note the rapid appearance time and steep baseline descent. $1 \mathrm{mV}=2 \mathrm{~mm}$.

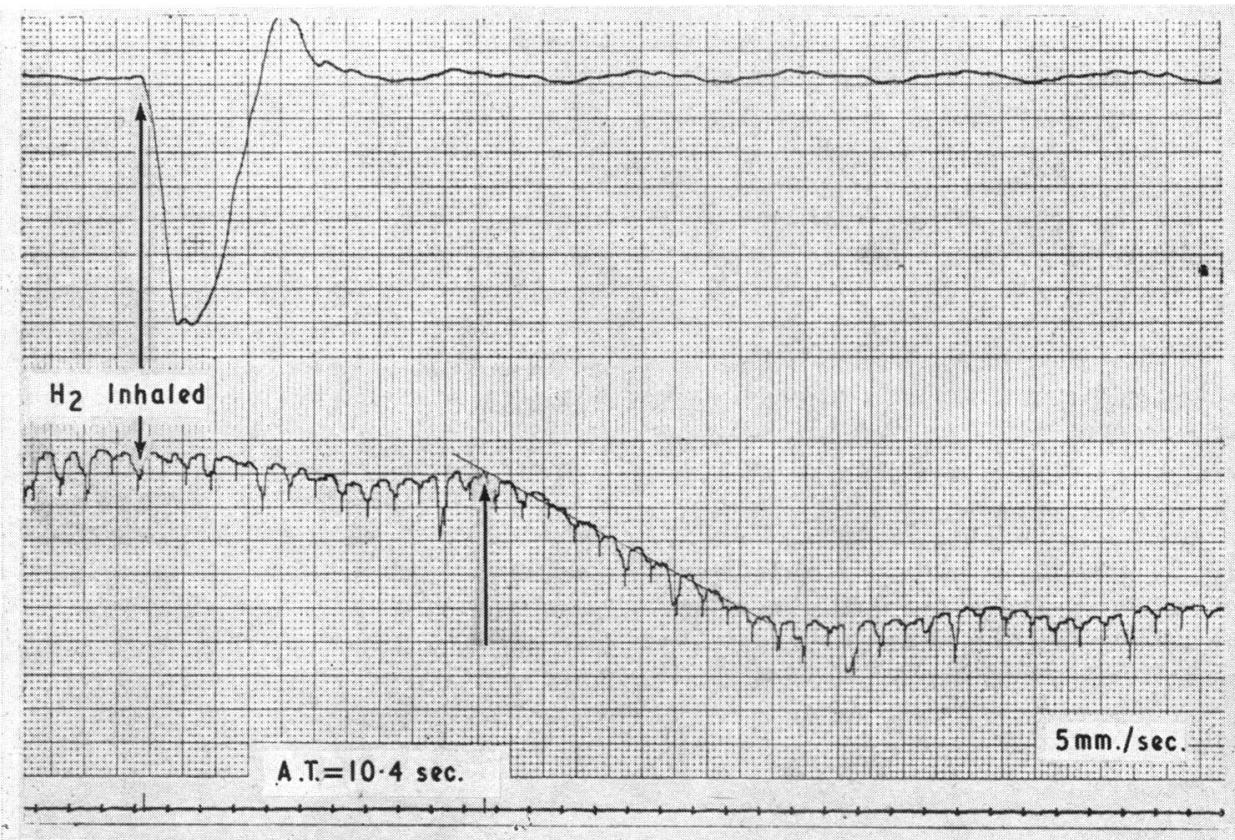

FIG. 2.-Negative response to hydrogen indicated by the prolonged appearance time and slow baseline shift. The platinum electrode catheter is in the main pulmonary artery. $1 \mathrm{mV}=2 \mathrm{~mm}$.

is the precise diagnosis of arrhythmias and tachycardias where the presence of $P$ waves on the electrocardiagram is uncertain, or where the precise origin of the $\mathbf{P}$ wave is not known. The introduction of the probe is so simple and free from discomfort to the patient that it is being used in acutely ill patients in the coronary care unit.
DETECTION OF VALVULAR INSUFFICIENCIES

In the presence of multiple valve disease it is not always possible to be certain of the presence or the severity of tricuspid or pulmonary valvular insufficiencies from clinical examination alone. Detection by means of indicator solutions using cardiogreen and similar dyes has been practised, and the 
bipolar platinum electrode has also been used successfully for the detection of such insufficiency (Collins, Braunwald, and Morrow, 1959; Frommer et al., 1961). Our technique was to use a bipolar platinum electrode and ascorbate as a source of $\mathrm{H}^{+}$ ions.

When the pulmonary valve is to be investigated, a bipolar platinum electrode as described above is introduced into the right heart chambers and the tip positioned in the main pulmonary artery. The proximal ring will then be in the body of the right ventricle. The exact position of both electrode rings can be determined from the electrocardiogram obtained on the oscilloscope. Once interference-free tracings are obtained, $250-500 \mathrm{mg}$. ascorbate diluted in a small volume of saline (to be determined by the dead space of the catheter) is injected as rapidly as possible, while simultaneous tracings from both electrodes are recorded, the instant of injection being marked on the tracing. The curves resemble the results of a dye dilution test: upstream of the valve there is an immediate and deep deflection, and, in the case of regurgitation, a slightly later and somewhat less deep deflection from the proximal electrode below the valve. Should the valve be competent, only a shallow delayed "recirculation" curve will be obtained. A similar method may be used for the estimation of aortic regurgitation (Schlant et al., 1962).

\section{Platinum Electrode as a Pacemaker}

The platinum electrode catheter placed in the outflow tract of the right ventricle can serve as temporary pacemaker. The proximal electrode terminal is connected to the outlet wire of the pacemaker. Pacing can then be continued for the desired length of time, meanwhile determining the influence of different rates on cardiac output, oxygen consumption, stroke volume, and so on. For obvious reasons, such a catheter cannot be left indefinitely in the heart but is certainly most useful in emergencies to control Stokes-Adams attacks, and during intubation and operation on a patient with heart block. From the patient's point of view a catheter pacemaker is much preferable to an external one.

\section{QUANTITATION}

It would be of great diagnostic value if, while detecting and localizing an intracardiac shunt, its magnitude could be determined as well. In order to do that it would be helpful if the area below the "dilution curve" were proportional to the magnitude of the shunt.

The recorders most commonly employed have an input impedance of about $1 \mathrm{M} \Omega$ or less, and were found to give a response which is neither linear nor fully logarithmic. Further difficulties are the slight variations in surface area of "identical" platinum electrodes and the extreme sensitivity of the system. Should one wish to use the system giving full logarithmic response, a high impedance system, well over $1 \mathrm{M} \Omega$, could be used (Hyman, 1961). Even this is unsatisfactory, however, as there is no zero in a logarithmic system, and very slight variations in concentration will give rise to large deflections of the curve. Should the reaction $\mathrm{H}_{2} \rightleftharpoons 2 \mathrm{H}^{+}+2 \mathrm{e}$ be valid, each $\mathrm{H}_{2}$ gives $2 \mathrm{e}$, and the relation is linear. Hyman (1961), using a low impedance transistor measuring circuit, showed that a linear response to hydrogen concentration could be obtained. The author tried to find a simple quantitative method using two identical platinum probes simultaneously. One was introduced into the pulmonary artery via an antecubital vein, while the other was introduced through a Cournand needle situated in the brachial artery, and advanced for about 8 in. $(20 \mathrm{~cm}$.). Each probe was connected to one of a two-channel electrocardiograph. The intracardiac (viz. intravascular) cardiogram was recorded simultaneously, the sensitivity of both being reduced to $1 / 5$ to $1 / 10$. A single breath of hydrogen was then administered, and a typical "dilution" curve was obtained simultaneously from both probes. It was hoped to demonstrate a relation between the two curves directly proportional to the flow in the arterial and the venous sides, respectively, hence showing the relative shunt (for example $2: 1$, or $3: 1$ ). It had not been appreciated at the outset of these experiments that the areas of the two probes were not identical, and that the gross difference in blood flow precluded drawing valid conclusions from the curves.

An elegant method for determining local blood flow with hydrogen gas has been described by Aukland, Bower, and Berliner (1964), but the apparatus required makes clinical use at the moment too cumbersome and expensive.

\section{Discussion}

The use of platinum electrode catheters and probes for routine cardiac catheterization has been shown to be easy, useful, safe, and cheap.

Constant monitoring of the intracavitary cardiogram is particularly helpful if such conditions as infundibular pulmonary stenosis, muscular subaortic stenosis, and Ebstein's anomaly are suspected; all of which are now amenable to surgical correction. On the intracavitary cardiogram, arrhythmia and such occurrences as touching the endocardium or displacing the catheter tip during the withdrawal of 
blood for sampling, entering the coronary sinus, or going through a septal defect, can be recognized at a glance.

The determination of oxygen saturation in blood samples is not always reliable or reproducible, and small shunts are probably sometimes missed. Hence, the use of hydrogen as a simple and safe indicator gas has now been accepted in many centres. In pædiatric cardiology, where numerous blood samples are not desirable, the use of hydrogen is helpful.

Especially convenient is the use of the platinum probe which can be introduced percutaneously in out-patients for detection of a small shunt or following the repair of a defect.

The same probe is a useful instrument for determining the nature of obscure arrhythmias and tachycardias. It can be used in the ward in quite sick people.

Detection of valvular insufficiency at cardiac catheterization without angiocardiography is not very satisfactory, and hence methods using dye dilution techniques have been developed. The introduction of ascorbate as an indicator has proved successful and easy to use. It can be repeated as many times as necessary without having to wait and without danger or discomfort to the patient.

Detection of right-to-left shunts is a more complicated procedure but Kaplan et al. (1961) have devised a technique using a polarographic anode and ascorbate.

Quantitation of shunts using platinum electrodes and hydrogen has been attempted but was found to be impractical with the standard electrocardiographs. Reliable methods of quantitation have been developed by Sanders, Cooper, and Morrow (1959) using nitrous oxide, and by.Hyman (1961) using hydrogen: they devised special recording apparatus measuring current rather than potential difference between the intracardiac and skin electrode.

Many people object to the use of the platinum electrode as electrocution hazards are feared. These do exist (Weinberg et al., 1962), but if a minimum of common sense precautions is taken, the procedure is as safe as an ordinary cardiac catheterization. Hydrogen is known to be an explosive gas, and its use in the presence of electrical equipment and in operating suites has been feared. It has recently been shown (Dickerson, Jensen, and Hollison, 1965) that the danger is minimal, but even this minimal hazard can be eliminated by having the patient exhale back into the bag as described above. The bag can later be emptied away from any electrical equipment.

\section{SUMMARY}

The routine use of a platinum electrode catheter for cardiac catheterization is of great diagnostic value, as constant monitoring of the intracavitary electrocardiogram enables accurate positioning of the catheter tip and demonstrates the presence of infundibular pulmonary stenosis, muscular subaortic stenosis, and Ebstein's anomaly.

Qualitative demonstration and localization of intracardiac shunts can be carried out easily, safely, and reliably with the same catheter, using hydrogen gas as indicator.

A screening test for possible left-to-right shunts can be carried out on out-patients, with the aid of a platinum probe, using the single breath hydrogen technique. The platinum probe is an invaluable tool for bedside diagnosis of arrhythmias.

The platinum electrode is also useful in determining valvular regurgitation, using ascorbate as the indicator solution. "Pace-making" for short periods can be accomplished in order to determine the influence of different rates on cardiac output as well as during implantation of a permanent pacemaker in a patient with complete heart block.

The investigation was supported by Grant HE 5448-04 from the United States Public Health Services. Thanks are due to Drs. H. N. Hultgren, E. W. Hancock, and many others of the Department of Cardiology, Stanford Medical Center, and to Dr. Z. Rotem for advice with instrumentation and for reading the manuscript of this report.

\section{REFERENCES}

Aukland, K., Bower, B. F., and Berliner, R. W. (1964). Measurement of local blood flow with hydrogen gas. Circulat. Res., 14, 164.

Clark, L. C., and Bargeron, L. M. (1959a). Left-to-right shunt detection by an intravascular electrode with hydrogen as an indicator. Science, 130, 709.

$\longrightarrow$, and $-(1959 \mathrm{~b})$. Detection and direct recording of left-to-right shunts with the hydrogen electrode catheter. Surgery, 46, 797.

Collins, N. P., Braunwald, E., and Morrow, A. G. (1959). Detection of pulmonic and tricuspid valvular regurgitation by means of indicator solutions. Circulation, 20, 561.

Dickerson, R. B., Jensen, W. L., and Hollison, R. V. (1965). The safety of hydrogen in shunt detection. Circulation, 31, 705.

Frommer, P. L., Pfaff, W. W., and Braunwald, E. (1961). The use of ascorbate dilution curves in cardiovascular diagnosis. Circulation, 24, 1227.

Glasstone, S. (1942). An Introduction to Electrochemistry, p. 350 . Van Nostrand, New York.

Hecht, H. H. (1946). Potential variations of the right auricular cavities in man. Amer. Heart $\mathcal{F}$., 32, 39.

Hugenholtz, P. G., Schwark, T., Monroe, R. G., Gamble, W. J., Hauck, A. J., and Nadas, A. S. (1963). The clinical usefulness of hydrogen gas as an indicator of left-to-right shunts. Circulation, 28, 542. 
Hyman, E. S. (1961). Linear system for quantitating hydrogen at a platinum electrode. Circulat. Res., 9, 1093.

Kaplan, S., Clark, L. C., Edwards, F. K., Gallaher, M. E., and Fox, R. P. (1961). Localization of right to left shunts with an intravascular polarographic anode sensitive to ascorbic acid. Amer. F. Cardiol., 8, 659.

Lenègre, J., and Maurice, P. (1945a). De quelques résultats obtenus par la dérivation directe intracavitaire des courants électriques de l'oreillette et du ventricule droits. Arch Mal. Cour, 38, 298.

- , and - (1945b). La dérivation directe, intracavitaire, des courants électriques de l'oreillette et du ventricule droits. Paris méd., 35, 23.

Misrahy, G. A., and Clark, L. C. (1956). Use of the platinum black cathode for local blood flow measurements in vivo. XXth International Physiological Congress, Brussels, Abstr. 650.

Sanders, R. J., Cooper, T., and Morrow, A. G. (1959). An evaluation of the nitrous oxide method for the quantification of left-to-right shunts. Circulation, 19, 898.

Schlant, R. C., Edwards, K. F., Rawls, W. I., Brinsfield, D. E., and Shuford, W. H. (1962). New method for estimation of aortic regurgitation. Circulation, 26, 782.

Sobol, B. J., Bottex, G., Emirgil, C., and Gissen, H. (1963). Gaseous diffusion from alveoli to pulmonary vessels of considerable size. Circulat. Res., 13, 71.

Sodi-Pallares, D., Estandía, A., Soberón, J., and Rodríguez, M. I. (1950). The left intraventricular potential of the human heart. II. Criteria for diagnosis in incomplete bundle branch block. Amer. Heart F., 40, 655 .

- Thomsen, P., and Soberón, J. (1948). New contributions to the study of the intracavity potential in cases of right bundle branch block in the human heart. Amer. Heart f., 36, 1.

Underhill, W. L., Hellerstein, H. K., Tredway, J. B., and D'Angelo, G. J. (1964). Localization of the aortic valve by intracavitary electrocardiography. Circulation, 29, 762.

Vogel, J. H. K., Averill, K. H., Tabari, K., and Blount, S. G. (1964). Detection of intracardiac shunts with the platinum electrode, using a simplified percutaneous approach. Amer. Heart f., 67, 610.

- , Grover, R. F., and Blount, S. G. (1962). Detection of the small intracardiac shunt with the hydrogen electrode. A highly sensitive and simple technique. Amer. Heartf. 64, 13.

$\longrightarrow,-$, and - (1963). The platinum electrode. (Annotation.) Amer. Heart $\mathcal{F}$, 65, 841.

Watson, H. (1964). Electrode catheters and the diagnostic application of intracardiac electrography in small children. Circulation, 29, 284.

Weinberg, D. I., Artley, J. L., Whalen, R. E., and McIntosh, H. D. (1962). Electric shock hazards in cardiac catheterization. Circulat. Res., 11, 1004.

Zimmerman, H. A., and Hellerstein, H. K. (1951). Cavity potentials of the human ventricles. Circulation, 3, 95 . 